\title{
EL PSOE Y LAS CUESTIONES COLONIALES (1890-1914)
}

\author{
por
}

\section{CARLOS SERRANO}

Universidad de Paris-Sorbonne

RESUMEN: El artículo procura analizar las actitudes del Partido socialista español ante los conflictos coloniales posteriores a la guerra de Cuba hasta la 1." guerra mundial. Se considera su actividad propia, asi como la insercion de su estrategia dentro del narco de las orientaciones propuestas por la Intentacional, mostrando la creciente radicalización del discurso, asi como la apertura, en dirección a los republicanos, que suscitan estos acontecimientos.

Palabras Clave. Soctalismo, Colonialismo. Marruecos.

ABSTRACT: The article analyses the attitudes of the Spanish Socialist Party towards the colonial conflicts after the Cuban war until the First World War. It own attitudes are considered, along with the insertion of its strategy into the framework of approaches proposed by the International, showing how the discourse becomes more radical and how these events encouraged a closer relationship with the Republicans.

KEY WORDS: Soctalism, colonialism, Morocco.

Los primeros pasos del socialismo en España estuvieron casi constantemente acompañados por la persistencia de unos graves problemas coloniales a los que tuvo que hacer frente la incipiente organización obrera. Esta situación creó hartas difícultades para los socialistas españoles, pero significó a su vez un gran avance en la plasmación de cierta práctica anticolonialista de los dirigentes del joven PSOE: otros investigadores, y yo mismo en alguna ocasión, hemos expuesto las grandes líneas de estas evoluciones que me parece bastará, por lo tanto, resumir muy sucintamente aquí.

Faltos de una doctrina coherente en materia colonial, influenciados por compañeros extranjeros, y singularmente franceses, que estaban divididos sobre este punto, sometidos a la presión patriótica y francamente colonialista 
de la mayoría de los republicanos, los socialistas españoles tardaron en determinar una postura, contentándose - como en 1892 en ocasión del $4^{\circ}$ Centenario del Descubrimiento, o en 1893, cuando los incidentes de Melilla- con denunciar genéricamente las políticas de los gobernantes y de una burguesía todavía vista de forma abstracta y general.

La guerra de Cuba, seguida de otra en Filipinas, el conflicto abierto con los Estados Unidos, precipitaron la toma de conciencia socialista en estas materias, en un momento en que, por otra parte, los eternos rivales anarquistas se habían quedado momentáneamente fuera de juego. En este sentido, la evolución de los socialistas desde 1895 —en que seguían mostrándose abstractamente pacifistas e ingenuamente colonialistas- y 1897-1898 — cuando ya eran activamente opuestos a la guerra y declaradamente internacionalistases notable y constituye un substrato definitivo para su actuación ulterior. Así es como, incapaces de impedir efectivamente unos conflictos que siempre vieron como impuestos de mala manera a los trabajadores, los socialistas espanooles tardaron en reconocer la legitimidad de las rebeliones cubana o tagala, pero no vacilaron en proclamar su solidaridad con los trabajadores de los Estados Unidos, ese $1^{\circ}$ de mayo de 1898 que vería los primeros enfrentamientos armados entre las dos naciones. La derrota sufrida por España en estas condiciones más bien resultó un alivio que otra cosa, al significar que Ios trabajadores dejarían de tener que ir, a falta de las pesetas necesarias para su redención del servicio militar, a una manigua justamente odiada!

Si las campañas de finales del siglo XIX no pudieron arrastrar a los socialistas por los senderos del patrioterismo al uso, menos lo lograrían entonces las expediciones "africanas" que tomaron el relevo con el cambio de siglo. De hecho, tras el «desastre» de 1898 y las primeras grandes operaciones por tierras marroquíes pasaron unos años de -relativa- paz, durante los cuales, no obstante, actuaron intensa y sigilosamente los diplomáticos. Esta discreción y esta aparente tranquilidad explican entonces que, prácticamente, la cuestión colonial no aparezca evocada para nada en los balances de fin de año que publica El Socialista entre el principio del siglo y 1905. Es más: en el informe presentado por la dirección socialista española en el congreso de la Internacional Socialista, reunida en Amsterdam en 1904, no se mencionaba siquiera el problema colonial ${ }^{2}$. No fueron suficientes siquiera las tensiones franco-alemanas en torno al imperio cherifiano, evocadas en julio de 1905 por El Socialista ("La guerra y el socialismo") para que el órgano del PSOE entrase a analizar la situación existente en el norte de Africa, tardando todavía hasta el

1 Serrano, C., Le Tour du peuple, Crise nationale, mouvements populaires et populisme en Espagne (1890-19/0), Madrid, Bibliothèque de la Casa de Velázquez, 1987, pág. 55 sq.

$?$ Salvo explicita mención contraria, las Actas de los Congresos de la lOS se citan por la edición de Ginebra, Minkoff reprint, de 1978 en adelante, publicados bajo la autoridad de Georges Haupt bajo el título genérico de Histoire de la $/ l^{*}$ Internationale. Los tomos 14 y 15 corresponden al Congreso de Amsterdam (1904), 16-18 al de Stuttgart (1907, pero no he podido consultar cl t. 17), 19-21 al de Copenhague (1910), 22 al de Basilea (1912). Para el caso de referencia, ver t. 15 , pág. 206-208.

Hixpteniat. LVHII/I, múm. 198 (1998) 283-304 
13 de octubre para mencionar la supuesta «penetración pacífica» española en Marruecos.

La situación a este respecto cambió brutalmente a partir de 1906 -a raíz de la conferencia de Algeciras-y, sobre todo, de 1907, cuando el congreso de la I.O.S reunido en Stuttgart definio, con hartas dificultades, una doctrina que el PSOE procuró entonces llevar a la práctica.

\section{A) 1906-1907: NUEVOS PLANTEAMIENTOS}

El 2 de septiembre de 1907, El Socialista -y tras él, los demás periódicos del PSOE- publicaron en primera plana el texto del llamamiento que los dos partidos socialistas de Francia y de España lanzaban a sus opinions respectivas, bajo el título de "A los trabajadores de Francia y de España». Este documentofirmado por Louis Dubreuilh, Bracke y Renaudel por la parte francesa, Pablo Iglesias y Mariano Garć́a Cortés por la española-iba encaminado a movilizar a los trabajadores de ambos países contra las políticas de sus gobiernos respectivos en Marruecos, y estaba concebido desde dos ópticas distintas y complementarias. En una primera parte, el documento denunciaba, en efecto, "la codicia de los capitalistas en busca de salida para sus productos y de los financieros a caza de especulaciones", así como los apremiantes riesgos de nuevas "matanzas de poblaciones indígenas" en Africa y de sacrificios de los «hijos del pueblon de los dos países implicados. Semejantes acontecimientos venían a desmentir formalmente la hipocresía de la mal llamada "penetración pacífica» y no eran más —en opinión socialista- que una manifestación más de la «civilización a cañonazos» que hacían imperar el capitalismo y los burgueses. La segunda parte, menos general, iba orientada más concretamente a la organización de una respuesta internacional de los trabajadores a la política de sus gobiernos, que tendría como objetivo oponerse a la nueva campaña militar bajo el lema de "Ni un hombre ni un céntimo para Marruecos». El manifiesto franco-español de los socialistas, amen de denunciar el hecho de que los proletarios serían los únicos en tener que soportar la carga de una nueva guerra, hacía valer, con la razón que a los pocos años se iba a ver, que unas hipotéticas victorias de las armas españolas o francesas tendrían como inevitable consecuencia la entrada de las demás potencias en el juego del reparto del botín, con el correlativo y peligroso acrecentamiento de las "probabilidades de conflictos internacionales". En resumen: el renovado intervencionismo militar francoespañol en Marruecos amenazaba a los «indígenas» y a los proletarios metropolitanos, haciendo además peligrar la paz mundial, todo ello por mor de la defensa de unos intereses particulares, los de ese "puñado de hombres dueños de los medios de producción" de que hablaba el manifiesto.

En realidad, este interesante documento no era el fruto de una iniciativa particular de los dos partidos firmantes, sino que era la primera manifestación concreta de la estrategia definida en su reciente (agosto de 1907) congreso de Stuttgart por la propia Internacional socialista, al que se alude por lo demás en el citado manifiesto franco-español. De hecho, la cuestión colonial se había 
revelado en Stuttgart como muy conflictiva en el propio seno de la Internacional. En nombre de la comisión destinada a preparar la resolución sobre este particular, el holandés H. Van Kol, había adoptado una actitud por lo menos moderada que, si bien denunciaba las fechorías capitalistas y el pillaje colonial, postulaba que las nuevas necesidades surgidas del propio desarrollo económico tras la victoria de la clase obrera «harían necesarias, incluso bajo el régimen socialista del porvenir, la posesión de colonias». La consecuencia de la línea adoptada por la mayoría de los congresistas resultaba entonces bastante contradictoria. Por un lado la resolución votada invitaba efectivamente a que los trabajadores se opusiesen «irreductiblemente a todas las medidas imperialistas o proteccionistas, a todas las expediciones coloniales, a todos los gastos para las colonias»; pero por otro se reconocía la posibilidad de la posesión de colonias por los futuros estados socialistas y se evocaba la posibilidad de una expansión colonial "pacífica», que provocó el declarado escepticismo del delegado francés Uhri ${ }^{3}$. Hubo más, puesto que se llegó a proponer un texto de resolución -finalmente rechazado por sólo 127 votos contra 108- en el que se estipulaba explícitamente que "el congreso [...] no repudia[ba] ni en principio ni para siempre toda forma de colonialismo, el cual, bajo un sistema socialista, podría cumplir una misión civilizadora” ${ }^{4}$.

En las mencionadas "Actas» del congreso de Stuttgart, no consta que los delegados españoles interviniesen, en un sentido o en otro. Pero, aunque no fuese más que por sus experiencias pasadas, es de suponer que sus simpatías, en este punto, iban hacia los representantes de la línea más opuesta a la aceptación de las colonias. En todo caso es de notar que la expresión pública del repudio de los socialistas españoles a las operaciones en Marruecos es bastante anterior al congreso de Stuttgart y no parece sufrir restricción alguna a raíz de este último. Es más, el Comité Nacional del PSOE adoptó el 27 de noviembre de 1906 un primer manifiesto, "iAlerta, trabajadores!" (firmado por M. García Cortés y P. Iglesias y publicado el 30 de noviembre) en el que se pretendía salirle al paso a la política de los gobernantes españoles en sus pretensiones africanistas. Y no vacilaba el Comité Nacional en poner en esta ocasión la necesaria lucha presente bajo el signo de sus luchas anteriores: «Lo realizado con nuestra clase en Cuba y en Filipinas fue horrible, fue cruel, fue monstruoso, y no debemos consentir que se repita", empezaba por proclamar el manifiesto, que concluía en estos términos:

«Nuestra protesta contra las guerras coloniales, la hicimos al grito de « $O$ todos o ninguno!»; hagámosla ahora, si se trata de llevarnos a una nueva matanza, al grito de «Ni un soldado a African».

No sin cierta sorna hacia la retórica entonces muy al uso, los dirigentes socialistas sugerían además que, de querer "civilizar y educar" como pren-

\footnotetext{
3 lbid., t. 16, pág. 320.

4 Berstein, E. (y otros), La 2." Internacional y el problema nacional y colonial (1." parte), «Jntroducción», Leopoldo Marmura, México, Siglo XX] ed, 1978, pág. 14.

Hiwania. LVIII/, uน่ı. 198 (1998) 283-304
} 
tendían, los gobernantes españoles no necesitaban ir a Africa, puesto que en España misma tenían materia suficiente para realizar su labor... Dos semanes más tarde, el 14 de diciembre, El Socialista repetía su advertencia a los trabajadores. Bajo el simptomático título de “i Alerta, siempre, obreros!» en primera página, el semanario llamaba la atención de los trabajadores sobre la inminente ratificación por el Parlamento de los acuerdos de la conferencia de Algeciras: «Háblase de un pacto secreto entre España y Francia, y si ese pacto existe, bien pudiera ocasionar dentro de poco una sangría al proletariado español», decía el texto, que, de momento, se contentaba sin embargo con llamar a un reforzamiento de la organización socialista.

La desconfianza de que hacían alarde los socialistas era harto fundada, como bien es sabido. Por lo pronto, y a pesar de lo acordado en Algeciras, la tensión renacía en Marruecos a principios de 1907, provocando nueva manifestación pública del órgano socialista que, en primera página siempre, volvía a enarbolar a modo de título la vieja consigna del "i $O$ todos o ninguno!", advirtiendo además de su determinación con las siguientes palabras:

"[...] la clase proletaria espanola, segura de que con su actitud realizaría obra verdaderamente patriótica, debe estar muy alerta para oponer en cualquier momento la más enérgica y desesperada resistencia a cuanto pueda conducimos a la repetición de aquella sangría suelta de las guertas coloniales y a la insensata renovación del nefasto "hasta el último hombre y hasta la última peseta" formulado por alguno de nuestros estadistas de guardarropía, responder con el más viril "iO todos o ninguno!" que sintetiza la más resuelta oposición a toda aventura guerreras.

De cierto modo, los socialistas se mostraban en esto un poco prisioneros de su propio éxito: la vieja fórmula había ganado tanto prestigio, que la repetían ahora, cuando en realidad significaba cierto retroceso frente al grito alternativo de "ni un soldado a Africa» que en un primer momento habían experimentado. Pero acaso no les era dable proceder de otro modo. Esto es, por lo menos, lo que parece desprenderse del artículo publicado el 30 de agosto ("¿Error o mala fe?") en el que el semanario socialista trataba de aclarar las posturas de los socialistas en materia de patriotismo. Frente a las interpretaciones - supuestamente ignorantes o malévolas-de aquellos que, tras el congreso de Stuttgart precisamente, afirmaban haberse producido un giro nacionalista en las filas de la Internacional, El Socialista reafirmaba su fideli dad a las convicciones de siempre, pero haciendo hincapié en la necesaria prudencia ante toda expresión de un radicalismo maximalista en estas materias; y aducía el ejemplo de su situación presente:

«Por haber expuesto nuestro criterio acerca de la cucstion marroquí y defender, ya que no esté en nuestra mano impedir la guerra, la necesidad de que vayan a ella, en caso de declararse, pobres y ricos -criterio con el cual se hallan conformes algunos elementos no socialistas-, se nos aplica la ley de Jurisdicciones como si hubiésemos cometido un delito de lesa patría. ¿Qué no ocurriría si se adoptase en todas partes la consigna de oponerse por la fuerza y en todo momento a cualquier choque entre las naciones?".

Hisponit, LVIII/, ním. 198 (1998) 283-304 
Como quiera que sea, el tono de alarma iba creciendo en las columnas de El Socialista, que en sus números correspondientes a los 16 y 23 de agosto confirmaba su hostilidad a todo lo que parecía poder presagiar unas operaciones militares a raíz de los incidentes de Casablanca - de que habían sido víctimas unos europeos- y de la réplica vigorosa que aquellos habían provocado por parte de Francia.

Este trasfondo de inquietudes nacidas de una experiencia y una historia genuinas, explica entonces la convicción con la cual los socialistas españoles acogieron las consignas de Stuttgart, de las que ya el 13 de septiembre se hacía eco El Socialista («Guerra a la guerra»), hablando del futuro "cumplimiento de los acuerdos del reciente congreso socialista internacional" referentes a Marruecos y del mitín que Jaurés acababa de realizar en el Tivoli-Vaux Hall ante 6000 participantes sobre el mismo tema, mientras la semana siguiente, el 20 de septiembre, anunciaba ya, con « $\mathrm{A}$ impedir la guera!», la inminente publicación del llamamiento conjunto franco-español antes evocado.

La publicación de dicho documento marca sin duda alguna un importante hito en la historia del partido socialista español. Salvo error mio, ésta era la primera vez en efecto que el PSOE participaba en una acción internacional concertada con otro partido, dando cuerpo a un internacionalismo, hasta entonces más verbal que efectivo. En principio, la campaña internacional pre vista debía iniciarse - y así lo anunciaba el mismo número de El Socialista con dos grandes mítines, uno en París y otro en Madrid, el 6 de octubre; un dirigente francés - no se especificaba cuál de ellos- vendría al de la capital española mientras Pablo Iglesias haría el viaje a París. Y, en un principio, los dirigentes españoles se mostraron confiados en el éxito: «Las circunstancias son favorables a esta acción" - léese el 4 de octubre en El Socialista ( Contra la guerra») - "El ambiente social es tan opuesto a la guerra con Marruecos [...] [que] bastará que los socialistas españoles, que cuantos obreros simpatizan con sus doctrinas y siguen su táctica se pongan en movimiento y realicen reuniones, para que una fuerte opinión les secunde y la labor por ellos emprendida cause en todo el país honda huella». El periódico, reiterando su invitación a aplicar las decisiones de Stuttgart, daba a continuación una especie de modo de empleo de la campaña que se lanzaba, cuyo objetivo era congregar a la mayor cantidad de gentes posible para manifestar públicamente una hostilidad a la guerra que quedaría patentizada en un texto sometido al voto de los ahí reunidos y para el cual el órgano socialista ofrecía el modelo siguiente:

"Al presidente del Consejo de Ministros

Las ciudadanas y los ciudadanos reunidos en el mitin celebrado en este día en el (teatro, Centro Obrero o el local que sea) reclaman del Gobierno que no envíc más tropas a Marruecos, que retire las que hay en Casablanca y que respete la independencia de dicho país. Esto demandan a una la humanidad y la civilización, los intereses de nuestro pueblo, y muy principalmente los intereses de la clase trabajadora.» 
De hecho, la parte efectiva de la campaña prevista se inició con un percance: los gobiernos francés y español, al alimón, decidieron impedir la acción conjunta prevista y expulsaron uno a Iglesias de Francia y otro al diputado socialista Willem de España, dando así ocasión a que El Socialista equiparase el 11 de octubre al republicano Clemenceau con el monárquico Maura ( "Contra la guerra»). Sin embargo, a parte de este obstáculo absurdo opuesto por los dos gobiernos implicados, la campaña pudo desarrollarse normalmente. En España se inició, como estaba previsto, en Madrid, en un acto presidido por Largo Caballero en el Frontón central - cuyo arriendo costó en esa ocasión 650 pesetas, teniendo además que pagar los organizadores «varios jornales» para la construcción de la tribuna ${ }^{5}$ - y que congregó una «enorme concurrencia, que no bajaría de ocho mil personas, entre ellas bastantes mujeres" en opinión de los redactores de El Socialista ("Contra la guerraCampaña internacional», 11 de octubre); se protestó contra la expulsión de Iglesias y de Willm (sic), se afirmó la necesidad de oponerse a las expediciones coloniales y a la guerra; se evocaron los precedentes del siglo anterior, así como la solidaridad manifestada en 1870 por socialistas franceses y alemanes. Por fin se clausuró el acto con la prevista votación de una moción que Largo Caballero comentó, bajo los aplausos del público en los siguientes términos:

"Cuando las guerras coloniales, nuestro lema era "O todos o ninguno". Ahora es más radical; "Ni un hombre ni una peseta»».

Como detalle significativo de la progresiva plasmación de un modelo constituido de actuación pública de los socialistas, el mitin con toda su parafernalia, transcribo a continuación el final de la descripción del acto en ese mismo artículo:

\begin{abstract}
«Acto seguido, el Orfeón Socialista sube a la tribuna y, antes de comenzar a cantar, el compañero Mora explica la costumbre que existe en todas les reuniones socialistas del Extranjero, donde los oyentes, al final de las reuniones, entonan todos cantos revolucionarios, singularmente La Marsellesa de la Paz y La Internacional, y ruega hagan lo propio los concurrentes.

A continuación se cantan los himnos de la Internacional y La Marsellesa de la $\mathrm{Paz}$, que despierta indecible entusiasmo y son acompañados por la concurrencia, terminando el acto a las doce en medio del mayor orden. $n$
\end{abstract}

Tras este brillante arranque - que tuvo stı correlato parisino el día 5 de octubre en la sala de "Sociétés Savantes" de la capital francesa-, la campaña se prolongó con numerosas reuniones y actividades en provincias, de las que El Socialista dio cumplida cuenta en sus sucesivos números. El Iunes 14 tuvo lugar el mitin de San Sebastián —en el Círculo Obrero, quedándose muchos concurrentes fuera del local, de tan lleno como estaba éste-, el 15 en Vitoria

5 Actas de asamblea-Agrupación socialista de Madrid, Fundación Pablo lglesias AASM-LXX2, pág. 59, sesión del 26-X-1907. 
-en el Circo, con 3000 participantes-, el 16 en Burgos - ante unas 1000 personas congregadas en un "vasto salon". Esta cronología escalonada se debía a la presencia en todos los mencionados actos de Pablo Iglesias; pero en otros lugares la campaña pudo comenzar antes, y así es como el 13 se celebró el mitín en Elche, el 8 en Torre del Valle, el 13 en Oviedo, en Bilbao -en el frontón Euskalduna, ante una concurrencia "extraordinaria» y con intervención de Perezagua entre otros--, en Avilés -en el Centro de Sociedades obreras "lleno totalmente»-. No siempre era posible lograr un acto público, como lo prueba el llamamiento que en su número correspondiente al 25 de octubre $E l$ Socialista lanzaba a todas las agrupaciones del partidos, instándoles a no descuidar la campaña lanzada e invitando aquellas que no pudiesen celebrar mitin a que enviasen su protesta al jefe del Gobierno, como así lo hizo por ejemplo la Agrupación de La Coruña.

En la lista de los actos realizados, aparecen obviamente las localidades de tradicional presencia socialista, como La Arboleda, Gallarta, Ortuella, Eibar o Sestao en Euzkadi, Mataró o Manresa, Reus, además de Tarragona y Barcelona, y, acaso más innovador, Sitges y Vich, para Cataluña; por Levante, los focos obreros habituales de Alcoy, Alicante, Crevillente, Játiba...; en Galicia, los de Vigo, El Ferrol, Lugo, Orense y Pontevedra...; en Asturias, en Gijón, Langreo o Avilés; en la meseta central, desde Salamanca, Valladolid, Toledo, Palencia, a centros como Medina de Rioseco, Rueda, Mora de Toledo o Miranda de Ebro. Como se ve, al lado de las grandes aglomeraciones o de los centros de ya afirmada presencia socialista, el PSOE logra penetrar en regiones o ciudades en que estaba menos arraigado y son así notables sus progresos por Andalucía - consiguiendo actos, además de Málaga y de Vélez-Málaga, en Sevilla, en Almeria, en Jaén, y también en el Puerto de Santa María- o en numerosos pueblos de muy diversas provincias - Corrales de Zamora, Campillos, Boadilla de Ríoseco, San Julián de Musques, Obregón, Teba, Puebla de Cazalla, Martos, LLuchmayor, etc. En total, y siguiendo las informaciones que publicó el órgano central del partido socialista prácticamente hasta final del año 1907, Ilegaron a casi al centenar las aglomeraciones en las que, de una forma u otra y las más veces mediante la organización de un mitin público, las organizaciones socialistas expusieron su aversión por los acontecimientos de Marruecos y la guerra.

La campaña de 1907 representó indudablemente un logro organizativo del PSOE, si bien, como era de prever, no logró pesar lo suficiente para modificar la pólitica oficial de España. Los efectos de semejante operación política no podían hacerse notar inmediatamente. A más largo plazo, la actuación socialista de aquel año puede haber desempeñado un nada desdeñable papel, como ahora se verá.

Por lo pronto, y pasada ya la parte más dinámica de la campaña anti-belicista, la hostilidad socialista a las operaciones en Marruecos siguí expresándose, pero de forma mucho más episódica, en los meses ulteriores. En febrero de 1908, El Socialista protestó contra el hecho de que tropas españolas de Melilla se apoderasen de la Mar Chica («La mano en el avispero", 21-II-08) mientras el 13 de marzo el C.N. del PSOE, haciendo hincapié en los peligros 
que la cuestión colonial representaba para los trabajadores, los instaba por lo mismo a que participasen con más decisión que nunca en la próxima celebración del $1^{\circ}$ de mayo en estos términos:

«[... ] la cuestión de Marruecos obliga este año a los obreros españoles a procurar con mayor empeño, con más ardor y con la decisión más resuelta que la movilización de $1^{\circ}$ de mayo en nuestro país sea más pujante que nunca. Nadie ignora que los hombres que ocupan el Gobierno tratan de hacer intervenir a España en los asuntos de Marruecos y que esa intervención será un hecho, ocasionando enormes males, si una fuerte opinión y una actitud de resistencia no se oponen a esta locura.,

Si la hostilidad a la guerra se repitió en diversas ocasiones a lo largo de este mismo año 1908, indudablemente el tema había dejado de estar en el candelero: buen testimonio da de ello el hecho de que el VIII congreso del partido, que tuvo lugar en el verano y de que El Socialista dio cuenta el 4 de septiembre no abordó prácticamente un tema, cuyo interés fue decayendo hasta volver a surgir, brutalmente, en el segundo semestre de 1909.

\section{B) LA CRISIS DE 1909}

La crisis de 1909 se ha estudiado generalmente a través del prisma -por otra parte justificado- de la explosión anticlerical y de la Semana Trágica barcelonesa: la "Ciudad quemada», con sus conventos humeantes, y la ejecución de Ferrer, con sus repercusiones internacionales, han solido si no silenciar por lo menos dejar en un modesto segundo plano lo que en realidad fue el motivo desencadenante de la crisis, esto es, la cuestión marroquí y la actuación socialista.

De hecho, la tensión antibelicista es perceptible desde mediados de junio, cuando El Sociatista publica en primera plana y bajo el titular de «Estemos alerta", un primer aviso, dando a conocer el hecho que el Gobierno acababa de solicitar un crédito de tres millones de pesetas destinados a unos preparativos militares de mal agüero y pronosticando que dentro de poco se iba a movilizar tropas destinadas a los presidios . Si bien, en ese mismo artículo, los redactores socialistas declaraban no creer en "la inminencia de una campaña de conquista en Marruecos», la situación les parecía suficientemente seria como para poner en guardia a los trabajadores y, como consta en ese mismo número del semanario socialista, favorecer la celebración de un primer mitin "contra la guerra" (pág. 4), a cargo de las Juventudes socialistas madrileñas, anunciado en los siguientes términos:

“En previsión de que los gobernantes pretenden arrastrar al país a una guerra con Marruecos, la Juventud Socialista Madrileña se previene y al efecto quiere manifestar públicamente su opinión en contra.

Por las calles de Madrid ha repartido un enérgico manifiesto contrario a la guerra y expresando su firme propósito de exigir que en el caso de hacerse inevita- 
ble el conflicto, no vayan a exponer sus vidas solamente los hijos de los pobres. El próximo domingo, a las diez de la mañana, celebrará un mitin de protesta contra los belicosos preparativos que se vienen haciendo. El acto tendrá efecto en el teatro Barbieri, Primavera 7,"

El documento traduce una neta evolución de los socialistas en estas materias, pero al mismo tiempo revela algunas de sus contradicciones. Por una parte era una real innovación, y un signo de remozada fuerza, que por una vez se anticiparan los acontecimientos y se atreviesen, si bien a través de las Juventudes, a organizar la lucha de forma preventiva: era signo de que se tenía ya otra ambición que la de protestar después que se hubiese producido, para tratar de impedir; antes que se produjera, la movilización militar. Por otra parte, esta firmeza nueva quedaba un poco empañada por el sentimiento de una desconfianza en sus propias fuerzas que rebosaba el documento, al recurrir una vez más al argumento de siempre, el famoso "o todos o ninguno", que se estaba convirtiendo así en auténtica muletilla del discurso anticolonial de los socialistas. Esta dualidad de actitud o, por lo menos, de discurso allora muy claramente en la forma misma como se expresaron los diversos oradores, según reseño El Socialista del 25 de junio ( Mitin de protesta contra la intervención de España en Maruecos»). Si todos hicieron referencia a los antecedentes de la guerra de Cuba, protestaron en términos generales contra los conflictos bélicos y las empresas coloniales y hasta hubo alguno que aludió a los intereses de Romanones en el asunto, Tomás Angulo recomendó "la protesta en tanto que no se consig[uiera] la implantación del servicio militar obligatorion, mientras García Cortés adoptaba un tono muy insólito en su dureza, llegando a afirmar:

"[...] Los socialistas vamos por la ley, pero si hubiese necesidad, arrostraríamos todos los peligros como lo saben hacer los hombres que sienten una idea».

Obviamente, el mitin madrileño fue un primer signo de que el PSOE había optado esta vez por una línea mucho más dura de la que le era habitual y estaba dispuesto a ir al enfrentamiento político abierto con el poder. Por lo demás la el propio C.N. del partido daba a conocer sus consignas en las nuevas circunstancias adoptando el día 28 de junio un manifiesto "Contra la guerra" destinado a «todos los trabajadores», publicado el 2 de julio. Por lo pronto, la dirección socialista parecía querer seguir la pauta de sus acciones anteriores, denunciando el envío de 20000 hombres a Marruecos, pintando todas las miserias que amenazaban a los proletarios en caso de guerra, y volviendo una vez más al tema de la injusticia de la ley de reclutamiento. La única innovación en este terreno era la aparición de un nuevo tema, el del militarismo, cuyo peligro razonaban sagazmente los autores del manifiesto de esta forma:

«Lo que ahora le falta, un caudillo capaz de sobreponerse a los hombres civiles, lo tendría entonces, porque es Africa sitio adecuado para que conquisten laureles los militares de los países que se denominan civilizados».

Hispania. LVIII/1, nu்m. 198 (1998) 283-304 
Las modalidades de acción, sin embargo, seguían siendo las de siempre, y el llamamiento tuvo como consecuencia una nueva oleada de mítines por todo el país, que el órgano central socialista empezó a reseñar a partir del 16 de julio. En Madrid, con García Cortés, Francisco Mora y Pablo Iglesias que, bajo la presidencia de Largo Caballero, denunciaron la política española en Africa, deploraron la muerte de unos obreros españoles pero se negaron a culpar por ellas a los marroquíes - que en la contienda eran quienes tenían la razón, llegó a afirmar Mora. Más concretamente, Iglesias supo ver que los acontecimientos que se estaban desarrollando no eran más que los preliminares de un plan general que sólo empezaba a desarrollarse y que por lo tanto amenazaba prolongar el incipiente conflicto. En Salamanca, en León, en Santander o Murcia, en Valencia, se organizaron -o se trató de organizar, puesto que en esta última localidad la autoridad prohibió el acto-mítines de idéntico corte (23-VII-1909); así mismo se repitió la actuación madrileña -en el teatro Lux Eden de Chamberí esta vez, y no ya en el Variedades tradicional- en sustitución de una manifestación anunciada pero inmediatamente prohibida por el Gobierno. Se repitieron los consabidos argumentos, a los que a se añadió esta vez la protesta por la prohibición de la manifestación. El rasgo más sobresaliente de dicha reunión fue, sin embargo, el tono adoptado por Pablo Iglesias que llegó a declarar que en caso de que un reservista del ejército «realizase un acto de venganza hundiendo un puñal en el pechos de alguno de los políticos de turno, él no lo condenaría sino que hasta lo aplaudiría ( $i !$ !), terminando su intervención con estas palabras:

«Deben todos los obreros tomar esta cuestión con el interés que correponde; deben las mujeres de los obreros ayudarles, tanto en el terreno pacífico como en el de la acción, si es preciso llegar a él. En este caso, solamente he de dar un consejo a los proletarios: no tiréis a los de abajo, tirad a los de arriba».

Estas últimas consideraciones provocaron el previsible revuelo, debiendo justificarlas ulteriormente Iglesias explicando que no había querido sino invitar los proletarios a no equivocarse de responsables a la hora de sacar las cuentas de sus desgracias. Como quiera que sea, quedaba claro que la directiva socialista estaba radicalizando su discurso, y acaso la concepción misma de su acción. Hasta ese momento la protesta desarrollada parecía deber repetir experiencias pasadas con sus resultados previsibles: éxito relativo de movilización en los lugares de implantación socialista, cierto impacto de "imagen" como se diría hoy, y, en el fondo, poco más y, en todo caso, una escasa incidencia efectiva en la política nacional. Pero el propio gobierno de Maura fue quien se encargó de modificar este apacible panorama, al salirle al paso al PSOE y querer prohibirle sus manifestaciones. Frente a lo que se le antojo una verdadera agresión, la dirección socialista no tuvo más salida que hacer gala de su firmeza: «no retrocederemos» afirmó El Socialista el 23 de julio; y el día siguiente el C.N. del partido, bajo la firma de Iglesias, redactó un nuevo comunicado - publicado el 30 - en el que por primera vez en su historia el 
partido socialista optaba por unas formas de acción radicales, expuestas en las siguientes líneas:

«El Partido socialista cumplirá con su deber. Hasta aquí ha procedido legalmente; legalmente procederá aún; pero si eł camino de la legalidad se le cierra, fuera de la legalidad ejerecerá su acción. Prohibidas las manifestaciones, prohibidos los mítines; secuestradas las hojas y los periódicos en que se combate la guerra, todavia le queda un recurso legal que emplear: la huelga general."

Como se puede comprobar en la cita anterior, la huelga política se consideraba como la última forma de acción legal que se le ofrecía a los socialistas. De hecho, esta argumentación era discutible, puesto que la figura de una huelga política no estaba contemplada como tal en la legislación imperante. De todas formas, legal o ilegal, esta referencia a la huelga representaba ya de por sí un enorme paso en la vía de la adopción de nuevas modalidades de acción proletaria. Pero, por si fuera poco, el comunicado firmado por Iglesias sugería que, llegado el caso, los socialistas podrían ir más allá y salirse totalmente de la legalidad: "si entran los hombres que hoy gobieman por las vías del terror, los socialistas responderán en ese terreno [...] y llegarán a aquellos extremos que juzguen eficaces para que caigan los más culpables», rezaba el mencionado documento...

Joan Connelly Ullman ha documentado suficientemente los acontecimientos ulteriores ${ }^{6}$ para que no sea necesario entrar de nuevo en una descripción promenorizada de los mismos. Como es sabido, los dirigentes socialistas, y singularmente los de Cataluna encabezados por Fabra Ribas, decidieron finalmente ir a una huelga general, cuyo inicio precipitado no permitió la generalización al resto del país y desembocó en las violencias de Barcelona. En los días y las semanas que siguieron los acontecimientos, la represión durísima, simbolizada en particular por la ejecución de Ferrer, cerró centros obreros y clausuró periódicos. Progresivamente se fue sin embargo a una lenta recuperación de la normalidad constitucional, con la cual los socialistas, que entre tanto habían recibido el apoyo de la propia Internacional (13-VII-1909), pudieron reanudar su expresión pública, lanzar una suscripción para los detenidos y manifestar su ya definitiva voluntad de lucha a muerte con el gobierno Maura. Esta se concretó en una nueva y amplia campaña de reuniones públicas y mítines desarrollada a lo largo del mes de octubre, en que se pedían conjuntamente la inhabilitación de Maura, la amnistía de los condenados, la expulsión de las órdenes religiosas «estén o no concordadas" y, evidentemente, la terminación de la guerra del Rif ${ }^{7}$... Culminó esta ofensiva en las grandiosas manifestaciones conjuntas de socialistas y republicanos (El Socialista , 29--X-1909) que desembocarían en la famosa "conjunción" y la voluntad declarada del propio Iglesias de obrar

- Connelly Ullman, J., La Semana Trágica. Esfudio sobre las causas socioeconómicas del anticlericalismo en España (1898-19/2), Barcelona, Ariel, 1972.

7 La Aurora Social, 29-IX-1909, Fundación Pablo Iglesias, pág. 334.

Hi.spania, LVIII/I, nu่m. 198 (1998) 283-304 
nada menos que para la instauración inmediata de la república. ( Los socialistas y la situación política en Españan, El Socialista , 19-XI-1909). Pero sobre todo, el retorno a la normalidad ciudadana y la caída de Maura permitieron que los socialistas dieran a conocer su versión de los acontecimientos del verano. La Aurora Social (órgano de la Federación Asturiana del Partido Socialista Obrero, según rezaba el subtítulo) reprodujo, por ejemplo, una carta fechada desde París, 27 de octubre, en la que Fabra Ribas desmentía que Ferrer hubiese tenido parte alguna en la preparación de la huelga de Barcelona y reafirmaba la validez de la actuación de los trabajadores catalanes y de los socialistas:

“[...] Sentimos naturalmente la muerte de los soldados españoles que caen en los campos de batalla; pero sentimos igualmente el sacrificio que se impone en vidas y haciendas a esos habitantes del Rif que no han cometido otro crimen que el de querer y defender su territorio con igual tesón y con idéntíco derecho que los españoles defendieron el suyo en 1808 contra las tropas de Napoleón. [...] Se nos reprocharán las violencias cometidas durante los acontecimientos de Julio. Pero ¿y las violencias que se cometen contra los moros? ¿No son estas mucho más grandes y mucho más inicuas que aquellas? [...]

Los portaestandartes del catolicismo nos deshonran y nos humillan ante Europa. La vida debemos jugarnos para acabar con ellos y evitar que ellos acaben con España [...]n ${ }^{8}$.

Más que una causa, el anticlericalismo resultaba ser de este modo una consecuencia de los acontecimientos del verano, y venía a teñir con colores nuevos la protesta antibelicista de los socialistas. Así es como, por ejemplo, en el relato que de "Los sucesos de Barcelona" publicó El Socialista a partir del 29 de octubre, se hacía constar que una de las cosas que más habían contribuido a exasperar los ánimos había sido la presencia en el embarque de tropas de «empingorotadas señoras que repartían escapularios y otras baratijas a los muchachos, no pocos de los cuales los echaron al agua desde la cubierta del mismo vapor»(29-XI-1909); o se declaraba justificada la alegría con la que se había acogido en el pueblo el primer incendio de convento -el de los Escolapios-, por la "invasión clerical" que padecía muy particularmente Barcelona (19-XI-1909). Sin embargo, en el balance de fin de año que, tradicionalmente, hacian los socialistas, publicado el 31 de diciembre, se borraba toda dimensión anticlerical en la actuación de los meses anteriores, siendo sólo reivindicada la oposición a la guerra en nombre de los «acuerdos internacionales" que la "Sección española de la Internacional Socialista» (me pregunto si no es ésta la primera vez que surge esta denominación) se debía de cumplir. Es más, ya dentro de esta línea, los dirigentes socialistas trataban de sacar un provecho político directo de lo ocurrido, presentándose como los únicos portavoces de la protesta popular legítima como demuestran estos párrafos:

8 Ibid., 19 XI 1909, Fundación Pablo Iglesias, pág. 346.

Hispania. LVIII/I, mün. 198 (1998) 283.304 
«[...] Estuvimos solos, completamente solos en los momentos de más peligro; esto nos da derecho a reclamar exclusivamente para nosotros la gloria que en ello pueda caber. Pero ni el estar solos ni el sufrir persecusiones debilitó nuestro ánimo ni causó vacilaciones: por encima de todo estaba nuestro deber y liegamos hasta donde se pudo llegar. Ir más allá hubiera sido insensatez en tales circunstancias."

Esta preeminencia reivindicada en la dirección de la lucha contra la guerra recibió un ulterior aval de la dirección de la propia Internacional que expresó su solidaridad con los socialistas españoles a través del siguiente mensaje de felicitación:

«Au parti socialiste espagnol et aux ouvriers d'Espagne et de Catalogne qui, si héroïquement, ont lutté pour empêcher l'expédition marocaine, pour mettre à exécution la résolution de I'Internationale à Stuttgart, le B.S.I. adresse ses félicitations, l'expression de son admiration et l'assurancer de sa solidarité fraternelle."

Ulteriormente, el Congreso de la IOS reunido en Copenhague entre el 28 de agosto y el 3 de septiembre de 1910 reiteraría su apoyo, adoptando por unanimidad la moción presentada por Rosa Luxemburg y Longuet, que, recogiendo la sustancia de la anterior declaración, le añadía una protesta por el "asesinato seudo-jurídico» de Ferrer y las debidas felicitaciones por la elección a diputado de Iglesias, en la que creían ver «el signo decisivo del despertar de la conciencia de clase de los trabajadores españoles” ". Pero lo que acaso fuera entonces más significativo de la auténtica reinterpretación de los hechos que se iba fraguando en la cúpula socialista, fue el informe que en nombre de la directiva del PSOE redactaron para el congreso Francisco Mora y Francisco Núñez. Después de haber reiterado que los socialistas sólos habían emprendido la lucha (esta afirmación apuntaba a los republicanos) y afirmado que los militantes socialistas habían procurado impedir la salida de los soldados en las estaciones de ferrocarril, reivindicaban la iniciativa en la organización de la huelga, que, prevista para el día 3 de agosto, se había iniciado el 25 de julio por culpa de "provocaciones gubernamentales». Pero el punto más relevante del informe era acaso la descripción que, en su peculiar francés, hacían los autores de la derivación anticlerical de los acontecimientos, frente a la que tomaban ahora sus distancias:

"Le mouvement, qui d'après les organisateurs de la grève devait se maintenir dans des limites tranquilles, degagea en révolution anticléricale par un élan naturel du peuple, irrité par les mauvaises nouvelles de la guerre. Depuis ce moment, les révoltés, n'obéissant les mots d'ordre, brûlèrent quelques couvents à Barcelone, après avoir fait sortir leurs habitants, et coupèrent les chemins de fer et les

9 Ambos documentos en Histoire de la IF Internationale, op. cit., t. 19, pág. 137, 310 y 497; versión castellana mía, C.S.

Hispania, LVIII/1, nủm. 198 (1998) 283-304 
fils téléphoniques et télégraphiques dans les villages d'alentour. [...] Si nous, les socialistes ne préparâmes ce mouvement, nous devons l'accepter comme une conséquence de la situation où l'on voulait maintenir le peuple, et dans ce sens nous avons défendu partout le spontané mouvement des masses.» 10

Solidarios con las masas, pero ajenos a los desmanes anticlericales los socialistas procuraban encabezar de este modo una protesta popular que tenía que prolongarse en el presente. En efecto, ni la gravedad de los acontecimientos del año anterior, ni siquiera la caída del gobierno Maura habian puesto un término a las operaciones en el norte de Africa. Tan era así, por lo demas, que desde por lo menos el mes de marzo de 1910 El Socialista había vuelto a llamar la atención de los trabajadores sobre lo que se estaba tramando en Melilla ( ¡Alerta, trabajadores!, 11-III-1910»), mientras las Juventudes socialistas seguían denunciando la redención a metálico en el ejército. Es más: los asuntos de Marruecos y las explicaciones sobre el comportamiento socialista en la crisis de 1909 fueron el objeto de los primeros discursos parlamentarios del novel diputado Pablo Iglesias "'. Por otro lado, aprovechando la oportunidad del VIII Congreso de la IOS, las delegaciones francesa y española sometieron a los delegados ahí congregados una nueva moción que, recogiendo las posturas ya tradicionales en esta materia, invitaba a todos los partidos socialistas y a todos los trabajadores a que prestasen su apoyo a las luchas que unos y otros se vieran obligados de llevar a cabo en el futuro en estas materias ( EI VIII Congreso de la Internacional Socialista en Copenhague», El Socialista , 16-IX-1910, pág. 2). En las semanas siguientes, el órgano central de los socialistas españoles siguió dedicándole un gran espacio al tema africano, a través de la crónica que, bajo el título genérico de "Nuestra acción en Marruecos», empezó a publicar ese mismo 16 de septiembre 1910 el recién incorporado a filas socialistas Manuel Ciges Aparicio. Pero en lo relativo a estos temas, la represión no cejaba, a pesar de gobernar ahora el liberal Canalejas: Ciges, a raíz de sus artículos, fue perseguido por la autoridad militar y tuvo que escapar a París (El Socialista, 30-IX-1910, pág. 3 y 18-XI-1910), y las actas" de la Agrupación socialista de Madrid revelan que los participantes en un mitin organizado en noviembre contra la guerra de Marruecos habían sido detenidos ${ }^{12}$. Por su parte, J.J. Morato hace alusión a una asamblea que se habría organizado en Madrid, con dos representantes de la CGT francesa, en ese mismo año 1910, del que sin embargo no tengo constancia ${ }^{13}$. Sin embargo, la firma del convenio por el cual el Sultán de Marruecos y le gobierno español declaraban querer poner un punto final a los

10 "Rapport du Parti Socjaliste Ouvrier espagnol», Histoire de la IF Internationale, op. cit., t. 20, pág. 1170; cito en el francés textual del documento.

"I IGLESias, P., Escritos y discursos, Antología crítica (ed. E. Moral Sandoval), Santiago de Compostela, Sálvara, 1984.

12 "Actas», op.cit., 4-XI-1910, pág. 137 y 137 bis.

13 Morato, J. J., El Partido socialista obrero, Madrid, Ayuso, 1976², pág. 193. Posiblemente se confunda aquí Morato con lo ocurrido en 1912 de que se habla más adelante. 
conflictos pendientes fue acogida con cierto optimismo ( El tratado [...] ha alejado por ahora la posibilidad de un choque», leíase en el balance de final de año de El Socialista ) y, en todo caso, como un éxito de la presión popular: el porvenir no tardaría en mostrar lo ilusorio que era ese análisis.

\section{C) 1911-1914: HACIA LA GUERRA}

Es de sobra conocida la creciente tensión internacional que fueron provocando los acontecimientos marroquíes en víspera de la primera guerra mundial para volver sobre ello ahora. Pero el nefasto juego tripartita anglo-franco-alemán en aquella zona tenía como inevitable correlato una presencia española, a la que, por otra parte, siempre se mostraron favorables los dirigentes españoles. La conjunción de exigencias geo-políticas internacionales y de ínfulas imperiales castizas condenaban a la impotencia las minoritarias manifestaciones de pacifismo o de anticolonialismo que promovía un PSOE en busca de una estra* tegia: apenas repuesto de sus emociones debidas al desenlace de la crisis de 1909 , volvieron a amontonarse las nubes del intervencionismo militar y, ya en la primavera de 1911, El Socialista tuvo que reanudar sus sempiternos avisos contra los riesgos que hacía correr a la paz la situación en el imperio marroquí: el 14 de abril Ciges Aparicio, desde París, mandaba un trabajo sobre "El embrollo marroquí, el 21 de abril, con "Insistiendo", el órgano socialista reafirmaba su inquietud, y el 5 de mayo pasaba ya a hablar claramente de una más que probable «conquista de Marruecos" por parte de Francia y España que, amparándose en los acuerdos de Algeciras, se iban a aprovechar de la rebelión de algunas tribus para restablecer el orden y asentar su poderío. Y frente a esta colaboración colonizadora franco-española, el semanario madrileño juzgaba oportuno reafirmar, mediante las publicación de sendos artículos de Jean Jaurés, una comunidad de vista anticolonialista franco-española - por lo visto puesta en tela de juicio por algunos- de los trabajadores de ambos países.

Esta labor de propaganda rebasó pronto la dimensión meramente periodística, y, ya a mediados de mayo, el partido socialista tuvo que renudar reuniones públicas contra la guerra («Ir contra la corriente», 12-V-1911). Lo realmente innovador, sin embargo, era que ahora el PSOE lograba arrastrar en una campaña de esta índole sus aliados republicanos, harto discretos, por cierto, en materias coloniales hasta aquella fecha. El 19 de mayo, El Socialista anunciaba en el artículo "Con la opinión", que el Comité de la Conjunción estaba preparando una campaña de actos públicos en este terreno, que cobraba toda su trascendencia después de que los franceses se hubiesen apoderado de Fes e implantado el consiguiente protectorado de hecho sobre el Imperio (2-VI-1911), provocando nuevas apetencias españolas en la zona norte.

El punto de partida de esta nueva -y repetitiva - batalla se produce en Madrid, con un mitín de la Conjunción en el que se lee un mensaje de Galdós (ausente por causa de enfermedad) que habla de la "cruzada patriótica» que desarrollan los conjuncionistas contra las "románticas aventuras belicosas" y concluye líricamente así:

Hispunia. LVIIJ/, nim. 198 (1998) 283-304 
"Quiero transformar los leones de mi escudo, no dejando otra fiera que la necesaria para defender el solar nativo, Quiero reconstruir mis castillos heráldicos en forma de viviendas regaladas o de talleres, donde se albergue la actividad fecunda de la Ciencia y de las Artes.» ("Campaña contra la guerra-El mitin del domingon, 30-VI-1911).

Iglesias, que intervino en el mismo acto, fue más sobrio al parecer, contentándose con repetir los tradicionales argumentos socialistas en contra de la guerra y recordando a los trabajadores lo que les habían costado las campañas de Cuba o Filipinas.

Actos parecidos se repitieron las semanas ulteriores en otras capitales españolas, en medio de una creciente tensión internacional, a la que contribuía no poco la inopinada presencia alemana en el puerto de Agadir. El mitín celebrado en Valencia por la conjunción (7-VII-1911) repitió los argumentos ya desarrollados en Madrid, pero añadiéndose una condena de la actitud de Alemania. Sólos (como en Madrid el domingo 9 de julio) o, más generalmente, con los republicanos (como en Barcelona, a pesar de la violenta postura hostil adoptada por unos lerrouxistas, cuya actitud "patriótican les llev6 a querer reventar el mitin, según escribe El Socialista , 21-VII-1911), los socialistas se lanzaron nuevamente a la palestra del antibelicismo, con nuevos mítines, en Bilbao, Castellón, Vigo, San Sebastián, Gijón, Alcoy, Sabadell, Eibar, Osuna, etc., pero también en lugares de menor trascendencia como el Puente de Vallecas, Santomillano, La Arboleda, Sopuerta, Begoña, Rute, o incluso en pueblos rurales como Alhaurin el Grande (!), Villamartín, etc. Claramente, la unidad de acción entre republicanos y socialistas, y la creciente implantación de éstos últimos, permitió una manifestación de la protesta en un ámbito geográfico mucho mayor que el alcanzado en las anteriores campañas. Pero sobre todo esta campaña fue cobrando otro rasgo innovador, al convertirse en verdaderamente internacional, organizándose por iniciativa esta vez de la IOS actos en Toulouse (convocado por los Partidos socialistas francés y español), París, Berlín (con la presencia de delegados de la C.G.T. francesa, El Socialista, 4-VIII-1911), Hamburgo, o Madrid, donde la convocatoria la realizó la Casa del Pueblo por mandato de la UGT española y de la CGT francesa, representada en el mitin por dos delegados ( $\mathrm{L}$ a Internacional obrera contra la guerran, 11-VIII-1911). García Cortés resumió bastante bien en esta ocasión el optimismo que de semejantes fraternizaciones podían sacar los militantes obreros:

"[...] Aunque se trate de llevarnos a la guerra, la fuerza de la juventud socialista en Alemania, Francia, Inglaterra y España imposibilitará que el crimen se perpetúe. Con pueblos tan conscientes como el inglés, el francés y el alemán no se juega. Los Gobiernos no podrán obligarles a hacer la guerra contra su voluntad, porque serán barridos. Ante el inevitable [sic] conflicto de una declaración de guerra, la Internacional obrera y socialista respondería con la huelga general y en el caso de fracasar esta huelga, aun le quedarían a la Internacional recursos extremos y eficaces". 
Por su parte, Francisco Mora sería más explícito si cabe, al precisar que en caso de guerra, surgiría «de nuevo la Commune, en Francia, Inglaterra, Alemania, Barcelona, Madrid y Bilbao».

El creciente vigor de la protesta pudo verificarse en el hecho de que ya en septiembre no se contentaron los socialistas con organizar mítines, sino que en numerosos lugares convocaron huelgas a través de la UGT. La importancia y el éxito, impresionantes, de esta agitación socialista inquietó realmente al Gobierno, hasta el punto de que Canalejas modificó la orientación de su politica, hasta entonces relativamente democrática, para lanzarse por la vía de la represión, llegando a prohibir en octubre nuevos actos públicos (El Socialista, 27-X-1911). El resultado de esta actividad es la que registró entonces el balance de fin de año (publicado en el número correspondiente al 5-I-1912):

"[...] Sin perjuicio de coadyuvar dentro de la Conjunción republicano-socialista a combatir la guerra [el PSOE] emprendió paralelamente, y en algunas ocasiones con los jóvenes socialistas, una campaña de protesta contra la guerra [...]. Esta campaña llegó a alcanzar carácter internacional y una de sus consecuen" cias fue la celebración de un mitin en París con asistencia de delegados españoles, y de otro en Madrid, al cual concurrieron delegados franceses."

Los dirigentes socialistas, y probablemente no sólo en España, demostraban en estas ocasiones un optimismo excesivo sobre su auténtica capacidad de respuesta a las políticas de sus gobiernos respectivos. De hecho, la campaña de 1911 marca como un punto culminante en la actuación socialista referente a los asuntos marroquíes, tras el cual se inicia un declive, práctico más que térico. Pueden, en efecto, seguir pregonando su hostilidad a la campaña rifeña los socialistas españoles ("Otra vez la guerra", 12-In1912), o expljcar "Como se engaña a la nación" (8-III-1912) a ese propósito; pueden, incluso, utilizar la tradicional celebración del $1^{\circ}$ de mayo para exigir el fin de la "guerra del Rif": nada impide que el gobierno prosiga, al alimón con Francia, su política de penetración en territorio marroquí, hasta llegar a ese «tratado con Francia» que glosa - negativamente, por supuesto-El Socialista el día 20 de diciembre, mostrando cómo se repartían el territorio marroquí «amigablemente, ya que no por igual, la monarquía española y la república francesan. El partido organizó la protesta contra esta ocupación, llegando a presentar al Gobierno un documento en este sentido, suscrito por 1611 colectividades afirma J.J. Morato. Pero, de hecho, ha perdido ya de tal modo la iniciativa y una verdadera capacidad de movilización que en el nuevo congreso de la Internacional socialista -reunida precipitadamente en Basilea los 24 y 25 de noviembre de 1912 para determinar una política ante las crecientes amenazas de guerra- es un militante italiano, Agnini, quien tiene que hablar en su nombre ${ }^{14}$. Reiterará Iglesias sus denuncias a lo largo del año 1913, y en los primeros meses de 1914, condenando los «delirios imperialistas" y los

\footnotetext{
14 Histoire de la $W^{*}$ Internationale, op.cit, t. 22, pág. 51.
}

Hispania, LVIIJ/, núm. 198 (1998) 283-304 
"colonistas" franceses a cuyo remolque va la política española ${ }^{15}$ Es más: afirma en varias ocasiones que «es deshonra nacional, opuesto al honor de la bandera, indigno para el Ejército y altamente incivilizador mantener una guerra como la de Marruecos» y que no se puede aducir la defensa de la civilización cuando se está "matando hombres, quemando aduares, llevando la desolación y el exterminio a un pals porque sus habitantes, hállense en el estado que se hallen, defiendan su independencian ${ }^{16 .}$ No obstante esta energía verbal, no logra el partido provocar el amplio movimiento de opinión que pudiera haber obligado a poner un término a las sangrías marroquíes, como lo muestra el éxito mitigado de la campaña de firmas lanzadas con este fin durante el primer semestre de 1914. El objetivo declarado era lograr un millón de firmas; pero cuando se dió por concluida la campaña, el 30 de junio, sólo se habría logrado reunir una escasa mitad de dicha cifra, cantidad de todas formas elevada en comparación con los votos socialistas, por no hablar del número de militantes ${ }^{17}$. Pero ya era tarde: en un alarde de energía, la UGT, apoyada por el C.N. del PSOE, "acordó organizar una huelga general de un día en protesta contra la ocupación de Marruecos", pero el inicio de la guerra europea desbarató el proyecto; no obstante, en el manifiesto publicado entonces el 2 de agosto por el partido socialista español para condenar la contienda que empezaba, se pedía "la paz entre los pueblos y, como consecuencia, el término de la guerra de Marruecos», según relata J.J. Morato ${ }^{18}$.

\section{D) EL PSOE Y LA CUESTIÓN COLONIAL}

De una forma u otra, las circunstancias hicieron que en ese primer cuarto de siglo largo de su existencia, el PSOE se viera confrontado de manera casi permanente con unos problemas coloniales para los cuales estaba poco armado conceptualmente y poca ayuda podía recibir de parte de sus congéneres extranjeros. El declive histórico de España en tanto que gran potencia hacía, en efecto, que los españoles tuviesen que abordar estas cuestiones desde una perspectiva de repliegue, en el mismo momento en que franceses, alemanes o ingleses tenían que enfocarlos a través del prisma de un expansionismo boyante. Esta situación particular tuvo como consecuencia una necesaria improvisación de los españoles, que se fueron forjando una doctrina sobre la marcha de los acontecimientos: ya pacifistas en 1895, pero no

15 P. Iglesias, Escritos y discursos..., op.cit., pág. 227-229.

16 Pablo Iglesias, articulo en Vida Socialista, 4-1-1914, recogido en Escritos 2, El Socialismo en España (artículos en la prensa socialista y liberal, 1870/1925), selección y estudio preliminar de Luis Arranz, Mercedes Cabrera, Antonio Elorza, Lydia Meijide y José Muñagorri, Madrid, Ayuso, 1972, pág. 263

17 Un estudio pormenorizado de la campaña en Andrée Bachoud, Les Espagnols devant les campagnes du Maroc (1909-1914) (thèse d'Etat pour le Doctorat), Paris, Université de la Sorbonne Nouvelle Paris-Ill, 1984, t. 2, pág. 536 sq.

18 Morato, J. J., op.cil., pág. 205-206. 
exentos todavía de confusos ramalazos colonialistas, fueron radicalizando su oposición a un conflicto que no se sintieron nunca con fuerza suficiente para combatir de frente y solos: su protesta adoptó, pues, la modalidad oblicua, pero popular, de la denuncia de la injusticia del servicio militar, el famoso "o todos o ninguno» que pasaría a la historia como la primera gran campaña nacional sobre un objetivo de política inmediata lanzada por el PSOE.

De algún modo, los acontecimientos ulteriores resultaban de más facil aprehensión por parte de los socialistas. Por un lado, a la inversa de lo que ocurría con Cuba y, en menor grado, con Filipinas, no existía apego alguno de los españoles por unos territorios a los que eran totalmente ajenos: por tanto, la denuncia de las pretensiones dominadoras españolas no podía chocar con un real sentimiento popular. Pero, además, existía ahora el precedente -que no dejó de recordar la propaganda socialista - de la guerra de Cuba precisamente, y de los nefastos recuerdos que dejaba en los medios populares. En este sentido, le resultaba más fácil al PSOE, por lo menos en el terreno moral y político, desenvolver sus repetidas campañas contra este nuevo conflicto que desarrollar su protesta contra la guerra cubana. Pero esto no significa necesariamente que tuviese una doctrina muy clara al respecto. De hecho, la oposición a la ley de reclutamiento militar siguió siendo, hasta su modificación en 1912, un eje (legítimamente) privilegiado en todas las proclamas socialistas, que solían insistir más en los desastrosos efectos de una guerra en España misma que en Africa. No obstante, al tratarse ahora de operaciones militares en tierras evidentemente de otros, los dirigentes socialistas no vacilaron nunca en reconocerles el derecho a defender su propia patria contra las agresiones exteriores. Pero este reconocimiento entrañaba, de hecho, no pocas ambigüedades: ¿qué es lo que se condenaba, la agresión armada o el colonialismo? No parece que la respuesta a esta pregunta estuviese muy clara entre dirigentes socialistas de aquel momento. "Penetrar a mano armada en un país de grado cultural inferior es, sin duda, mucho más fácil que penetrar en él pacífica y sabiamente, con los mil recursos que a los pueblos cultos proporciona la civilización", escribía en 1910 Julián Besteiro, para quien alemanes, franceses $\mathrm{y}$, sobre todo, ingleses, habian sabido recurrir a formas "pacíficas y sabias" de penetración en Marruecos, mientras España sólo lograba avanzar militarmente, para mayor ruina de su prosperidad y de su cultura ${ }^{19}$. De estas premisas, Besteiro derivaba rápidamente a una denuncia del propio personal político español, cuyos intereses le parecían estar estrechamente ligados a los de las empresas mineras, como lo explicaba en $\mathrm{El}$ Radical de los 27 y 28 de octubre de 1910 con estas líneas:

"Las tendencias militaristas de la monarquia española no pueden comprenderse claramente sino en su relación orgánica con la corriente capitalista y colonizadora y sin la consideración de los provechos materiales que, a una buena parte

19 Besterro, J., Obras Completas (ed. y presentación a cargo de E. Lamo de Espinosa), Madrid, Centro de Estudios Constitucionales, 1983, t. I, pág. I77 sq.

Hispania, LVIII/I, лúm. 198 (1998) 283-304 
de nuestros politicos, reporta el servicio de los intereses exclusivos del capitalismo y del Ejército. [...] Bueno seria, para tenerlo en cuenta a su debido tiempo, ir haciendo el registro más acabado posible de los gobernantes españoles que obtienen provechos del fomento de la política colonial, desde los accionistas de minas como Romanones, hasta los abogados de Empresas y representantes de Sociedades mineras, como los Sres. Dato y Moret, consejeros en España de los hermanos Mannesman" 20 .

Opuesto a las expediciones militares, denunciador de los intereses privados de los políticos en los asuntos coloniales y hasta, discretamente, acusador del papel del propio rey en estas aventuras, Besteiro trataba, sin embargo de sobrepasar la dimensión puramente contigente de estos elementos para tratar de alcanzar una comprehensión teórica de lo que él mismo llamó, en un mitin madrileño de marzo de 1911, el «imperialismo colonial», en pleno auge desde 1880, según él, debido a la competencia entre Inglaterra y las «naciones modernamente nacidas a la vida industrial» para repartirse las colonias. Besteiro, y con él los demás dirigentes socialistas, podían ocasionalmente hacer el elogio de los colonizados en su resistencia a las invasiones, o, no sin cierto masoquismo, declarar inferior la situación española a la de aquellas colonias; hasta, llegado el caso, sugerían que "la explotación inhumana de los proletarios de las razas inferiores» podía constituir «un peligro de ruina para los mismos trabajadores de la metrópoli»; pero no sacaban de estas premisas la conclusión política de una posible convergencia en la lucha de ambas partes, resolviéndose la propuesta de acción en un pacifismo generalizado, que, a nivel europeo, no tardaría en colapsar espectacularmente ${ }^{21}$. Pero, de hecho, yo diría que al margen de estas especulaciones, el anticolonialismo socialista español fue marginalmente ideológico y esencialmente pragmático y me parece que sus fundamentos distaban mucho de ser la "generosidad" y, más aún, ese «cristianismo» que le atribuye Andrée Bachoud ${ }^{22}$, asemejándose más al fruto de una experiencia vivida directamente por militantes y trabajadores a lo largo de todo el período.

En definitiva, la práctica concreta del PSOE en estas circunstancias fue de creciente compromiso y de creciente energía en la protesta, pasando de una denuncia platónica y moral de la guerra en 1895 a una campaña política contra su organización en 1897; y de este tipo de campañas políticas y propagandísticas a nuevas formas de acción, como esa huelga general que tanto desasosegaba a Pablo Iglesias, en 1909 y, virtualmente, en 1914. El examen de estas sucesivas experiencias muestra una creciente implantación territorial del partido en su capacidad de convocatoria, puesto que se pasa de unos 20 OOO congregados en unos 40 mítines de 1897, al centenar de reuniones logradas diez años más tarde, tras la conferencia de Algeciras, y el casi medio millón de firmas reunidas en 1914, pasando, claro está, por el papel relevante,

\footnotetext{
20 Ibid., pág. 210.

21 «En Madrid-Conferencia de D. Julián Besteiro», El Socialista, 8-111-1911, pág.1.

22 BACHOUD, A., op. cit., pág. 530 sq.
} 
a menudo obliterado por derivaciones ulteriores de los acontecimientos, que desempeñó la organización socialista en los sucesos de 1909. En este sentido, parece lícito afirmar que la práctica de los socialistas españoles en las guerras coloniales fue un importante punto de apollo de su creciente audiencia. En ella, la dirección propiamente española tuvo que improvisar una línea política específica, un poco a salto de mata, si bien lo hizo siempre dentro del marco general perfilado por la cúpula de la Internacional a través de las resoluciones adoptadas en los congresos de Londres en 1896 primero, los de Amsterdarn 1904 y, sobre todo, de Stuttgart 1907 luego, o sus directivas e impulsos más inmediatos recibidos en los momentos decisivos. Por fin, cabe subrayar que, en el plano interior, la cuestión marroquí de los primeros decenios de este siglo fue uno de los principales elementos que facilitaron la árida marcha del PSOE hacia esa unidad de acción con los republicanos, que tantos obstáculos había encontrado hasta entonces ${ }^{23 .}$

23 JULıÁ, S., Los socialistas en la política española (1879-1982), Madrid, Taurus, pág. 53-85.

Hispania, LVIII/1, núm. 198 (1998) 283-304 